Stoeber, J., Stoll, O., Pescheck, E., \& Otto, K. (2008). Perfectionism and achievement goals in athletes: Relations with approach and avoidance orientations in mastery and performance goals. Psychology of Sport and Exercise, 9(2), 102-121.

\title{
Perfectionism and Achievement Goals in Athletes: \\ Relations with Approach and Avoidance Orientations \\ in Mastery and Performance Goals
}

\author{
Joachim Stoeber, ${ }^{1}$ Oliver Stoll, ${ }^{2}$ Eva Pescheck, ${ }^{2}$ \& Kathleen Otto ${ }^{3}$ \\ ${ }^{1}$ University of Kent, ${ }^{2}$ Martin Luther University of Halle-Wittenberg, \\ ${ }^{3}$ University of Leipzig
}

\begin{abstract}
Author Note
We would like to thank Franziska Reschke and two anonymous reviewers for helpful comments and suggestions on an earlier version of this article; Andreas Lau for technical support with the automated data entry; and Sabine Würth for collecting data at the University of Leipzig. Correspondence concerning this article should be addressed to Joachim Stoeber, Department of Psychology, University of Kent, Canterbury, Kent CT2 7NP, United Kingdom; phone: +44-1227-824196; fax: +44-1227-827030; email: J.Stoeber@kent.ac.uk.
\end{abstract}




\begin{abstract}
Objectives: Challenging views that perfectionism is a maladaptive factor in sport and that it is related to a preoccupation with performance goals and a neglect of mastery goals, the present article argues that perfectionism in athletes is not generally maladaptive, but shows differential relationships with mastery and performance goals depending on which facets of perfectionism are regarded.

Method: Going beyond the dichotomous achievement goal framework, two studies with $N$ $=204$ high school athletes and $N=147$ university student are presented investigating how two facets of perfectionism - striving for perfection and negative reactions to imperfection (Stoeber, Otto, Pescheck, Becker, \& Stoll, 2007)—relate to athletes' achievement goals.

Results: Following the trichotomous achievement goal framework, Study 1 found striving for perfection to be positively related to mastery and performance-approach goals, whereas negative reactions to imperfection were positively related to performance-approach and performance-avoidance goals and inversely to mastery goals. Following the $2 \times 2$ framework, Study 2 found striving for perfection to be positively related to mastery-approach and performance-approach goals whereas negative reactions to imperfection were positively related to mastery-avoidance, performance-approach, and performance-avoidance goals. Moreover, negative reactions to imperfection predicted residual increases in mastery-avoidance goals over three months.

Conclusions: It is concluded that striving for perfection in athletes is associated with an adaptive pattern of achievement goals whereas negative reactions to imperfection are associated with a maladaptive pattern. Thus, striving for perfection in sport may be adaptive in athletes who do not experience strong negative reactions when performance is less than perfect.
\end{abstract}

Keywords: perfectionism; sport; achievement motivation; goal orientations; performance; mastery; approach; avoidance

\title{
Introduction
}

While some researchers have identified adaptive perfectionism as a key characteristic to achieve elite performance in sports (Gould, Dieffenbach, \& Moffett, 2002), others see perfectionism as a maladaptive characteristic that undermines, rather than helps athletic performance and thus represents an impediment to athletic development (Flett \& Hewitt, 2005; Hall, 2006). Consequently, athletes may face what Hewitt and Flett (2005) call the "perfectionism paradox:" Although in many sports athletes are expected to deliver perfect performances, perfectionism in athletes can be related to characteristics that may thwart performance. Regarding achievement goals, Flett and Hewitt propose that perfectionism is associated with a pervasive ego orientation, suggesting that perfectionists are preoccupied with performance goals and neglect mastery goals. Thus perfectionists may focus on proving their ability and neglect improving their ability, which in the long run will have detrimental effects on their performance. However, perfectionism is multidimensional and multifaceted, and only some dimensions and facets are clearly negative, harmful, and maladaptive whereas others are positive, benign, and possibly adaptive (Chang, 2003; Enns \& Cox, 2002; Stoeber \& Otto, 2006). In the present article, we will take a look at two facets of perfectionism in athletes-striving for perfection and negative reactions to imperfection-and show that only negative reactions to imperfection are related to a preoccupation with performance goals and mastery avoidance. In contrast, striving for perfection is re- 
lated to both mastery and performance-approach goals, indicating that athletes who strive for perfection show a pattern of achievement goals that may help rather than undermine performance.

Perfectionism is commonly conceived of as a personality style characterized by striving for flawlessness and setting of excessively high standards for performance accompanied by tendencies for overly critical evaluations of one's behavior (Flett \& Hewitt, 2002; Frost, Marten, Lahart, \& Rosenblate, 1990). However, research has suggested that two major dimensions be differentiated (Stoeber \& Otto, 2006): a positive dimension which has been described as normal, healthy, or adaptive perfectionism and a negative dimension which has been described as neurotic, unhealthy, or maladaptive perfectionism (Hamachek, 1978; Rice \& Preusser, 2002; Stumpf \& Parker, 2000; Terry-Short, Owens, Slade \& Dewey, 1995). The negative dimension of perfectionism subsumes those facets of perfectionism that relate to perfectionistic concerns such as concern over mistakes, doubts about actions, feelings of discrepancy between expectations and results, and negative reactions to mistakes. This dimension has been associated with negative outcomes, for example, test anxiety, fear of negative evaluation, and low self-esteem (e.g., Bieling, Israeli, \& Antony, 2004; Hill et al., 2004; Rice, Ashby, \& Slaney, 1998). In contrast, the positive dimension of perfectionism subsumes those facets of perfectionism that relate to perfectionistic strivings such as having high personal standards or striving for excellence. This dimension has been associated with positive outcomes, for example, higher academic performance, perceived ability to achieve, and endurance (Bieling, Israeli, Smith, \& Antony, 2003; Enns, Cox, Sareen, \& Freeman, 2001; Stumpf \& Parker, 2000). Consequently, the distinction between positive and negative facets of perfectionism may also prove crucial when investigating perfectionism and achievement goals in athletes.

In contrast to the classic approach to achievement motivation, which focuses on motives and investigates differences in how strongly individuals are motivated and energized, the contemporary approach to achievement motivation focuses on goals and investigates the different reasons why individuals are motivated to achieve (Elliot, 1997). In this endeavor, researchers have looked at achievement goals using different frameworks adopting first a dichotomous, then a trichotomous, and finally a $2 \times 2$ framework (Elliot \& Conroy, 2005; Moller \& Elliot, 2006). In the dichotomous framework, two achievement goal orientations were distinguished (Ames \& Archer, 1987; Dweck, 1986; Nicholls, 1984): an orientation towards mastery goals (also termed task goals or learning goals) and an orientation towards performance goals (also termed ego goals). Individuals with a mastery goal orientation see achievement situations as opportunities to improve their ability. They focus on learning new skills or improving old ones and regard failures and mistakes as providing important information on how to improve. In contrast, individuals with a performance goal orientation tend to see achievement situations as opportunities to prove their ability. Their goal is to demonstrate their ability relative to others, to show what they have learned and, if possible, to outperform others (Maehr \& Meyer, 1997). In the trichotomous framework (Elliot \& Harackiewicz, 1996; Skaalvik, 1997), a further distinction was introduced by differentiating approach and avoidance orientations in performance goals. Individuals with a performance-approach orientation are concerned with making a good impression: they want to demonstrate high ability relative to others. In contrast, individuals with a performance-avoidance orientation are concerned with avoiding making a bad impression: they do not want to perform worse than others. Thus, the trichotomous model differentiates between three kinds of goals: mastery, performance-approach, and performance-avoidance goals. Finally, in the $2 \times 2$ framework (Elliot \& McGregor, 2001; Pintrich, 2000), the distinction between approach and avoidance orientations was also applied to mastery goals. 
Individuals with an orientation towards mastery-approach goals aim to make the best of the situation and are confident of being able to do so, whereas individuals with an orientation towards mastery-avoidance goals are afraid of not being able to master the task or not making the best of the situation.

Regarding perfectionism and achievement goals in athletes, all studies so far have followed the dichotomous achievement goal framework and investigated relationships with mastery and performance goals only (Dunn, Dunn, \& Syrotuik, 2002; Hall, Kerr, Kozub, \& Finnie, in press; Hall, Kerr, \& Matthews, 1998; Ommundsen, Roberts, Lemyre, \& Miller, 2005). To measure perfectionism, the studies used the Frost Multidimensional Perfectionism Scale (Frost et al., 1990). As this measure captures two facets of perfectionism-personal standards and concern over mistakes - that have been identified as core facets of positive and negative perfectionism, respectively (Stoeber \& Otto, 2006), this allows for a reinspection of the studies' findings differentiating positive and negative facets of perfectionism. Hall et al. (1998) investigated mastery and performance goals in high school athletes who had registered to compete in a cross-country meet, measuring goals at two points of time: one week and 30 minutes before the competition. At both times, concern over mistakes was related to performance goals and unrelated to mastery goals. In contrast, one week before the competition, personal standards were related to both mastery and performance goals; and 30 minutes before the competition, personal standards were related to mastery goals only. Hall et al. (in press) investigated perfectionism and goal orientations in adult middle-distance runners. Again personal standards were related to both performance goals and mastery goals, whereas concern over mistakes was related to performance goals only. The same pattern was found by Dunn et al. (2002) with high school football players. Again, personal standards were related to both performance goals and mastery goals, and concern over mistakes was related to performance goals only. In addition, concern over mistakes was inversely related to mastery goals. Finally, Ommundsen et al. (2005) investigated perfectionism and achievement goals in adolescent soccer players. Personal standards were again related to both performance and mastery goals. In contrast, maladaptive perfectionism (which combined all other facets of the perfectionism measure, including concern over mistakes) was related to performance goals and, again, showed a small inverse correlation with mastery goals. In sum, the findings indicate that facets of positive perfectionism (such as personal standards) are related to both performance and mastery goals whereas facets of negative perfectionism (such as concern over mistakes) are related to performance goals. Moreover, facets of negative perfectionism may also show an inverse relationship with mastery goals.

So far, no study has gone beyond the dichotomous framework and investigated how facets of positive and negative perfectionism relate to goal orientations when an extended framework is adopted and approach and avoidance orientations are differentiated. Yet, such a differentiation would be important to further clarify the relationships between perfectionism and achievement goals in athletes. According to the dual process model of perfectionism (Slade \& Owens, 1998), positive perfectionism is characterized by cognitions and behaviors focused on approach goals, whereas negative perfectionism is characterized by cognitions and behaviors focused on avoidance goals. Consequently, it can be expected that facets of positive and negative perfectionism in athletes show differential relations with approach and avoidance orientations in mastery and performance goals. Moreover, going beyond the dichotomous achievement goal framework would allow an investigation into how patterns of achievement goals are related to different facets of positive and negative perfectionism. 
To this end, we conducted two studies. In Study 1, we looked at the trichotomous achievement goal framework and investigated how perfectionism relates to mastery, performance-approach, and performance-avoidance goals. In Study 2, we looked at the $2 \times 2$ achievement goal framework and investigated how perfectionism relates to mastery-approach, mastery-avoidance, performance-approach, and performance-avoidance goals. Regarding perfectionism, two facets were inspected-striving for perfection and negative reactions to imperfection (Stoeber, Otto, Pescheck, Becker, \& Stoll, 2007)—of which striving for perfection has been found to represent the core element of the positive dimension of perfectionism (Stoeber \& Otto, 2006) whereas negative reactions to imperfection which have been found to be intimately related to concern over mistakes and maladaptive perfectionism (Frost \& Henderson, 1991; Rice \& Preusser, 2002). As research has shown that athletes set different goals for training and for competition (e.g., Munroe-Chandler, Hall, \& Weinberg, 2004), it was conceivable that levels of perfectionism and relationships between perfectionism and achievement goals differed when training and competition were compared. Consequently, we also differentiated between perfectionism during training and perfectionism during competition.

Following the empirical findings from the previous studies on perfectionism and achievement goals in athletes (Hall et al., 1998, in press; Dunn et al., 2002; Ommundsen et al., 2005) and combining them with the predictions from Slade and Owens's (1998) dual process model of perfectionism, we expected striving for perfection to be related to mastery and performance-approach goals and negative reactions to imperfection to be related to performance-approach goals and inversely to mastery goals, when the trichotomous achievement goal framework was adopted. Moreover, we expected striving for perfection to be related to mastery-approach and performance-approach goals and negative reactions to imperfection to mastery-avoidance and performance-avoidance goals, when the $2 \times 2$ achievement goal framework was adopted.

\section{Study 1}

\section{Participants and Procedure}

\section{Method}

A sample of $N=204$ high school athletes (131 male, 73 female) was recruited at two athletics high schools (so-called "Sportgymnasien") in Saxony-Anhalt, Germany. Sportgymnasien are special high schools for students with outstanding athletic abilities and provide students with regular training sessions in various disciplines as an integral part of the school curriculum. Mean age of participants was 15.8 years $(S D=0.9$; range: 14-18 years). Questionnaires were distributed during classes. Participants were asked to indicate their main discipline (e.g., soccer, volleyball, track and field athletics) and to respond to all measures with respect to their main discipline only.

\section{Measures}

Perfectionism during training and competition. To measure perfectionism during training and competitions, the ten items from the Multidimensional Inventory of Perfectionism in Sport (MIPS; Stöber, Otto, \& Stoll, 2004) that Stoeber et al. (2007) used to differentiate striving for perfection and negative reactions to imperfection were employed. These items were presented once in the training format and once in the competition format so that five items each measured striving for perfection during training, negative reactions 
to imperfection during training, striving for perfection during competition, and negative reactions to imperfection during competition (see Appendix). ${ }^{1}$ Participants were asked to indicate how they usually felt during training and during competition responding on a 6point scale from "never" to "always." All scales displayed high reliability: striving for perfection during training (Cronbach's $\alpha=.89$ ), negative reactions to imperfection during training ( $\alpha=.82$ ), striving for perfection during competition $(\alpha=.90)$, negative reactions to imperfection during competition $(\alpha=.84)$.

Achievement goals. To measure achievement goals, the Scales for the Assessment of Learning and Performance Motivation (Spinath, Stiensmeier-Pelster, Schöne, \& Dickhäuser, 2002) were used which follow the trichotomous achievement goal framework differentiating mastery, performance-approach, and performance-avoidance goals. As the scales were originally developed to capture school students' achievement goals in the classroom, instructions and items were modified to capture athletes' goal orientations in their main discipline (Pescheck, 2005). Participants were asked to indicate their agreement with each item responding on a 6-point scale from "totally disagree" to "totally agree." After deletion of items with low item-total correlations, the final scales each comprised six items measuring mastery goals (e.g., "to learn as much as possible"), performanceapproach goals (e.g., "to show that I am good at what I am doing"), and performanceavoidance goals (e.g., "to avoid showing that I am weaker than others"). All scales displayed acceptable reliability (cf. Nunnally \& Bernstein, 1994): mastery goals ( $\alpha=.67$ ), performance-approach goals ( $\alpha=$.67), performance-avoidance goals $(\alpha=.82)$.

\section{Results}

In line with findings that athletes set different goals in training and competition (Munroe-Chandler et al., 2004), mean levels of perfectionism differed markedly between training and competition. High school athletes indicated greater striving for perfection during competition $(M=4.77, S D=1.04)$ than during training $(M=4.07, S D=2.96)$, $t(203)=11.41$, and reported more negative reactions to imperfection during competition $(M=3.41, S D=1.05)$ than during training $(M=2.96, S D=0.96), t(203)=8.05$, both $p s<$ $.001 .^{2}$ Moreover, striving for perfection and negative reactions to imperfection were significantly correlated during training, $r=.41$, and during competition, $r=.35$, both $p$ s $<$ .001 , indicating that it may be important to control for the overlap between the two facets of perfectionism (cf. Stoeber \& Otto, 2006; Stoeber et al., 2007). Thus, partial correlations were computed in addition to zero-order correlations when examining the relations between perfectionism and achievement goals (see Table 1).

\footnotetext{
${ }^{1}$ The reason for using the MIPS scales instead of the previously established measures of perfectionism in sport based on the Frost Multidimensional Perfectionism Scale (FMPS) (Anshel \& Eom, 2003; Dunn et al., 2006) was that the MIPS explicitly addresses striving for perfection whereas the FMPS rather addresses high personal standards and striving for excellence, which is not the same as striving for perfection (Flett \& Hewitt, 2006). Still, adapted versions of the MIPS scales have shown high convergent correlations with FMPS subscales as was demonstrated in a study with a large undergraduate sample in which striving for perfection showed a correlation of $r=.72$ with FMPS personal standards and negative reactions to imperfection a correlation of $r=.72$ with FMPS concern over mistakes (Stoeber, 2005). Finally, the scales to measure striving for perfection and negative reactions to imperfection during competitions have shown high factorial validity and a differentiated pattern of expected correlations with competitive anxiety in athletes (Stoeber et al., in press).

${ }^{2}$ Throughout the article, $p$ values are from two-tailed tests.
} 
First, perfectionism during training was inspected. As expected, striving for perfection was related to both mastery and performance-approach goals and negative reactions to imperfection were related to performance-avoidance goals. Moreover, when striving for perfection was partialled out, negative reactions to imperfection displayed a negative correlation with mastery goals. Unexpectedly, negative reactions to imperfection were also related to performance-approach goals. Next, perfectionism during competition was inspected. Correlations showed the same pattern as perfectionism during training, except for a partial correlation that indicated a weak inverse relationship between striving for perfection and performance-avoidance goals, once negative reactions to imperfection were partialled out. Else, the pattern of correlations was exactly the same as that for perfectionism during training: Striving for perfection was related to mastery and performance-approach goals whereas negative reactions to imperfection were related to performance-approach and performance-avoidance goals. Moreover, when striving for perfection was partialled out, negative reactions to imperfection displayed a negative correlation with mastery goals.

\section{Discussion}

The finding that striving for perfection was related to mastery and performanceapproach goals confirmed our expectations that striving for perfection in athletes is associated with an adaptive pattern of achievement goals and with approach motivation. Regarding negative reactions to imperfection, expectations were only partially confirmed however. On the one hand, negative reactions to imperfection were related to performanceavoidance goals and inversely to mastery goals corroborating expectations that negative reactions to imperfection in athletes are associated with a maladaptive pattern of achievement goals and with avoidance motivation. On the other hand, negative reactions to imperfection were also related to performance-approach goals. This was unexpected from the view of Slade and Owens's (1998) dual process model which holds that negative perfectionism is related to avoidance motivation, not approach motivation. Theory and research in educational psychology, however, suggests that performance-approach goals are associated with both approach and avoidance achievement motives and thus shown close relationships with hope for success and fear of failure (e.g., Elliot, 1997; Elliot \& Church, 1997; see also Conroy, 2004). Since striving for perfection has been shown to be related to hope of success and negative reactions to imperfection to fear of failure (Stoeber \& Rambow, in press), this may explain why both striving for perfection and negative reactions were associated with performance-approach goals.

To investigate if the positive relationship between negative reactions to imperfection and performance-approach goals would replicate in a different sample and to further investigate the differential relationships between perfectionism and mastery goals, a second study was conducted employing the $2 \times 2$ achievement goal framework comprising mastery-approach, mastery-avoidance, performance-approach, and performance-avoidance goals. Following Slade and Owens's (1998) dual process model and in line with the previous findings, we expected striving for perfection to be related to both mastery-approach and performance-approach goals and unrelated to avoidance goals. Regarding negative reactions to imperfection, the expectations were now more differentiated: following the dual process model, we expected negative reactions to imperfection to be related to both mastery-avoidance and performance-avoidance goals and unrelated to mastery-approach goals; following the educational psychology literature and the findings of Study 1, we expected negative reactions to imperfection also to be related to performance-approach goals. In addition, Study 2 aimed to explore whether striving for perfection and negative 
reactions to imperfection predict changes in athletes' achievement goals. Consequently, a longitudinal design was employed to investigate changes in achievement goals.

\section{Study 2}

\section{Participants and Procedure}

\section{Method}

A sample of $N=147$ students (90 male, 57 female) majoring in sport and exercise studies was recruited at the Institute of Sports Science, University of Halle and the Faculty of Sports Science, University of Leipzig, Germany. Mean age was 22.8 years $(S D=3.0$; range: 19-42 years). The first set of questionnaires was distributed during lectures at the beginning of the winter term (T1). As in the previous study, participants were asked to indicate their main discipline and to respond to all subsequent measures with respect to their main discipline only. In addition, students were asked to provide an individual code made up of numbers and letters pertaining to personal information (i.e., date and place of birth, mother's maiden name). At the end of the winter term, two to three months later (T2), the second set of questionnaires was distributed during lectures. Overall, the codes of $n=103$ participants (70\%) could be matched from T1 to T2, and the data from these participants were used for the longitudinal analyses.

\section{Measures}

Perfectionism during training and competition. To measure perfectionism during training and competition at T1, the same scales as in Study 1 were used. All scales showed again high reliability: striving for perfection during training $(\alpha=.93)$, negative reactions to imperfection during training $(\alpha=.82)$, striving for perfection during competition $(\alpha=$ .93), negative reactions to imperfection during competition $(\alpha=.84)$.

Achievement goals. To measure achievement goals at T1 and T2, the $2 \times 2$ Achievement Goals Questionnaire for Sport (Conroy, Elliot, \& Hofer, 2003) was employed, translated into German using a standard backtranslation procedure involving a native English speaker (Jany, Stoll, \& Lang, 2004). The questionnaire comprises four scales with three items each to capture mastery-approach goals (e.g., "It is important to me to perform as well as I possibly can”), mastery-avoidance goals (e.g., "I worry that I may not perform as well as I possibly can”), performance-approach goals (e.g., "It is important to me to perform better than others"), and performance-avoidance goals ("I just want to avoid performing worse than others"). At both T1 and T2, participants were asked to answer the items according to how they felt about their sport at present, responding on a 6-point scale from "disagree completely" to "agree completely." All four scales showed satisfactory reliability: mastery-approach (T1/T2: $\alpha=.74 / .86)$, mastery-avoidance $(\alpha=.85 / .83)$, performance-approach ( $\alpha=.85 / .87)$, performance-avoidance ( $\alpha=.77 / .82)$.

\section{Results}

First, the cross-sectional relationships at $\mathrm{T} 1$ were inspected. As in the previous study, mean levels of perfectionism differed markedly between training and competition. University student athletes showed higher levels of striving for perfection during competition ( $M$ $=4.52, S D=1.23)$ than during training $(M=3.64, S D=1.28), t(145)=10.68$, and more negative reactions to imperfection during competition $(M=3.26, S D=1.05)$ than during training $(M=2.59, S D=0.83), t(145)=10.35$, both $p s<.001$. Moreover, striving for perfection and negative reactions to imperfection were again significantly correlated during training, $r=.53$, and during competition, $r=.56$, both $p s<.001$. Consequently, as in 
Study 1, partial correlations were computed in addition to zero-order correlations to control for the overlap between the two facets of perfectionism (see Table 2).

Regarding striving for perfection, all correlations were as expected. Striving for perfection during training was related to mastery-approach and performance-approach goals and unrelated to avoidance goals. The same held for striving for perfection during competition, once partial correlations were computed to control for the overlap with negative reactions to imperfection. Regarding negative reactions to imperfection, all correlations were as expected too, once partial correlations were computed to control for the overlap with striving for perfection. However, only negative reactions to imperfection during competition were related to mastery-avoidance, performance-approach, and performanceavoidance goals and unrelated to mastery-approach goals, as was predicted. For negative reactions to imperfection during training, the partial correlation with performanceavoidance goals failed to reach significance, $r=.11, p=.21$, and the zero-order correlation was only marginally significant, $r=.15, p=.07$.

Next, the longitudinal relationships between T1 and T2 were inspected. To investigate whether striving for perfection and negative reactions to imperfection at T1 predicted changes in goal orientations from T1 and T2, a series of hierarchical regression analyses was conducted to analyze changes following the regressor variable approach (Taris, 2000). Because striving for perfection during training and during competition were highly correlated, $r=.68$, as were negative reactions to imperfection during training and during competition, $r=.68$, both $p<.001$, all scores were standardized and then the two measures of striving for perfection combined into a single measure of striving for perfection and the two measures of negative reactions to imperfection combined into a single measure of negative reactions to imperfection. Following this, four regressions were calculated, one for each of the $2 \times 2$ achievement goals. In Step 1 of each regression, the respective achievement goal orientation at T2 (e.g., mastery-approach T2) was regressed onto itself at T1 (e.g., mastery-approach T1). Then in Step 2, the combined measures of striving for perfection and negative reactions to imperfection at T1 were entered to investigate if they predicted any residual changes in the goal orientation from T1 to T2 (e.g., changes in mastery-approach from T1 to T2; see Taris, 2000 for details). For two of the four goal orientations, striving for perfection and negative reactions to imperfection at T1 predicted residual changes in achievement goals from T1 to T2 (see Step $2 \Delta R^{2}$ values in Table 3): mastery-approach goals and mastery-avoidance goals. Regarding the individual facets of perfectionism at T1, striving for perfection predicted residual changes in mastery-approach goals, but the effect was only marginally significant, $\beta=.18, p=.08$. In comparison, negative reactions to imperfection predicted residual changes in mastery-avoidance, and this effect was highly significant, $\beta=.29, p<.001$ showing that negative reactions to imperfection at T1 predicted residual increases in mastery-avoidance goals from T1 to T2.

\section{Discussion}

Regarding the cross-sectional findings, Study 2 replicated and further clarified the central findings of Study 1. Regarding striving for perfection, it replicated the finding that striving for perfection in athletes is related to performance-approach goals. Moreover, it clarified the relationship between striving for perfection and mastery goals found in Study 1 by showing that striving for perfection is related to mastery-approach goals, not masteryavoidance goals. Regarding negative reactions to imperfection, it replicated the finding that negative reactions to imperfection are related to performance-approach and performance-avoidance goals. Moreover, it clarified the inverse relationship between negative re- 
actions to imperfection and mastery goals found in Study 1 by showing that negative reactions to imperfection are related to mastery-avoidance goals, not mastery-approach goals.

However, one central finding of Study 1 was only partially replicated in Study 2: the correlation of negative reactions to imperfection with performance-avoidance goals was significant only for negative reactions to imperfection during competition, but not for negative reactions to imperfection during training. Moreover, the respective correlations were smaller in Study 2 compared to Study 1 (cf. Tables 1 and 2). A potential reason for this discrepancy could have been that athletes in Study 1 were younger and that fear of failure is more salient in younger athletes. Another reason could have been that the measure of performance-approach goals used in Study 1 had stronger negative connotations than that used in Study 2. Regarding the items of the two measures, the measure of performance-avoidance goals used in Study 2 (Conroy et al., 2003) solely focused on the avoidance of performing worse than others (i.e., avoid performing worse than others, avoid performing worse than everyone else, avoid being one of the worst performers in the group; Conroy et al., 2003) without further evaluating this performance negatively. In contrast, the measure of performance-avoidance goals used in Study 1 (Spinath et al., 2002; Pescheck, 2005) included items referring to the avoidance of showing weakness (e.g., avoid showing that I am weaker than others) and the avoidance of negative reactions of others following a bad performance (e.g., avoid that others think that I am a bad athlete, avoid making a fool of myself by showing bad performance). As a consequence, negative reactions to imperfection during training and during competition may have shown more intimate relationships with performance-avoidance goals in Study 1 compared to Study 2. While a comparison of three-tiered versus $2 \times 2$ models of achievement goals in relation to perfectionism was not a primary goal of our studies, future studies may consider measuring both models in one sample employing structural equation modeling to provide for a direct comparison of the two models.

\section{General Discussion}

The aim of the present research was to investigate further the relationship between perfectionism and achievement goals in athletes, differentiating between striving for perfection and negative reactions to imperfection (Stoeber et al., 2007). To this end, two studies were conducted and relationships with mastery and performance goals examined. In this, Study 1 followed the trichotomous achievement goal framework and investigated mastery, performance-approach, and performance-avoidance goals, and Study 2 followed the $2 \times 2$ achievement goals framework investigated mastery-approach, masteryavoidance, performance-approach, and performance-avoidance goals. Following the trichotomous framework, Study 1 found striving for perfection to be related to mastery and performance-approach goals whereas negative reactions to imperfection were related to performance-approach and performance-avoidance goals and inversely to mastery goals. Following the $2 \times 2$ framework, Study 2 found striving for perfection to be related to mastery-approach and performance-approach goals whereas negative reactions to imperfection were related to mastery-avoidance, performance-approach, and performanceavoidance goals. Moreover, Study 2 found that negative reactions to imperfection were associated with increases in mastery-avoidance goals.

The present findings demonstrate that perfectionism in athletes is not necessarily maladaptive, as a recent review on perfectionism in sport may suggest (Flett \& Hewitt, 2005). Instead, they show that striving for perfection is related to an adaptive pattern of achievement goals combining mastery-approach and performance-approach goals. Negative reactions to imperfection, however, are related to a maladaptive pattern of achievement goals 
including mastery-avoidance and performance-avoidance goals. Moreover, the present findings indicate that negative reactions to imperfection predict residual increases in mastery-avoidance goals over a period of three months. As was demonstrated in a recent longitudinal study that monitored motivation of participants in a summer swim league over a period of six weeks (Conroy, Kaye, \& Coatsworth, 2006), mastery-avoidance goals had a damaging effect on athletes' intrinsic motivation in that residual changes in masteryavoidance goals were positively linked to the rate at which amotivation increased over time. Consequently, negative reactions to imperfection, but not striving for perfection, illustrate the detrimental effects that negative perfectionism in sport may have (cf. Flett \& Hewitt, 2005; Hall, 2006). Finally, by showing that striving for perfection (when taken to represent positive perfectionism) is related to mastery-approach and performanceapproach goals whereas negative reactions to imperfection (when taken to represent negative perfectionism) are related to mastery-avoidance and performance-avoidance goals, the present findings provide further support for the dual process model of perfectionism (Slade \& Owens, 1998) which holds that positive perfectionism is related to approach motivation whereas negative perfectionism is related to avoidance motivation.

However, one central finding of the present studies does not fit well with the dual process model, namely the finding that negative reactions to imperfection were also related to performance-approach goals. While this finding may be unexpected from the view of the dual process model, it dovetails with findings from educational psychology that performance-approach goals are often maladaptive, and may be adaptive only if masteryapproach goals are also espoused (Midgley, Kaplan, \& Middleton, 2001). This view concurs with research in sport psychology, which has also produced mixed findings regarding performance-approach goals. While Cury, Da Fonséca, Rufo, Peres, and Sarrazin (2003) found that athletes who were instructed to adopt a performance-approach goal orientation did not show higher state anxiety than those who were instructed to adopt a mastery goal orientation, Conroy (2004) found performance-approach goals related to several dimensions of fear of failure, such as fear of experiencing shame and embarrassment, fear of important others losing interest, and fear of upsetting important others. Moreover, Ommundsen (2004) found that pursuing performance-approach goals without pursuing mastery goals was related to higher levels of self-handicapping, thus confirming Midgley et al.'s (2001) worries that performance-approach may be a "motivationally double-edged sword" (Ommundsen, 2004, p. 183). Consequently, it is important to look not only at the relationships of perfectionism with individual achievement goals, but at the pattern of relationships that perfectionism displays with achievement goals. When the pattern of relationships is regarded, then it is fitting that only striving for perfection was associated with performance-approach goals in combination with mastery-approach goals, whereas negative reactions to imperfection were associated with performance-approach goals in combination with mastery-avoidance and performance-avoidance goals, all of which have been found to be related to fear of failure (Conroy \& Elliot, 2004). Thus, the only achievement goal orientation that is completely positive is the mastery-approach goal orientation (see Moller \& Elliot, 2006), and that was the goal orientation that striving for perfection showed the closest relationship with.

The present findings may have some limitations, however. First, the present studies investigated high school athletes and university student athletes. Thus, the findings may be limited to student athletes and may not generalize to professional or elite athletes. As adaptive forms of perfectionism have been identified as a key characteristic of Olympic champions (Gould et al., 2002), future studies should investigate whether the present relationships can also be found in elite athletes. Second, the present research focused on two 
facets of perfectionism only, that is, striving for perfection and negative reactions to imperfection. Consequently, it is important that future studies replicate the present findings by employing different multidimensional measures of perfectionism in sport and investigating different facets associated with adaptive and maladaptive perfectionism (e.g., Anshel \& Eom, 2003; Dunn et al., 2006). Moreover, it is important to note that the two facets inspected in the present research differ in emotionality and temporal orientation: whereas the striving for perfection subscale captures self-assessments of the motivation to attain perfection and thus is cognitive and prospective (looking ahead), the negative reactions to imperfection subscale captures affective reactions to the non-attainment of perfection and thus is emotional and retrospective (looking back). ${ }^{3}$ Since differences in emotionality and temporal orientation between positive and negative aspects of perfectionism can also be found in other multidimensional measures of perfectionism (e.g., the high standards and discrepancy subscales of the revised Almost Perfect Scale; Slaney, Rice, Mobley, Trippi, \& Ashby, 2001), future research may profit from including concern over mistakes (Frost et al., 1990; Dunn et al., 2006) when measuring negative aspects of perfectionism because concern over mistakes captures cognitions directed at the future non-attainment of perfection and thus is cognitive and prospective, like striving for perfection. While we would not expect concern over mistakes to show a pattern of correlations different from that of negative reactions to imperfection (cf. Footnote 1), an inclusion of concern over mistakes would allow to investigate whether differences in emotionality and temporal orientation in measures of perfectionism do play a role in how positive and negative facets of perfectionism are related to achievement goals in athletes. Finally, while the present findings show that athletes display higher levels of perfectionism during competition than during training, perfectionism during competition and training showed the same pattern of relationships with achievement goals. The reason for this may have been that, while we differentiated between perfectionism during training and during competition, we did not differentiate between achievement goals during training and during competition. Consequently, future research on perfectionism and achievement goals comparing training and competition should include measures of achievement goals during training and during competitions taking into account that athletes may have different profiles of dominant achievement goals during training and competitions (Van Yperen, 2006).

Nonetheless, the present findings have important theoretical and practical implications for the understanding of perfectionism in sports. Regarding theoretical implications, they provide further support for the view that striving for perfection does not have to be a source of stress and distress, but may be part of a healthy pursuit of excellence and be associated with adaptive outcomes if self-worth is not made contingent on success or failure to achieve perfect results (DiBartolo, Frost, Chang, LaSota, \& Grills, 2004; Shafran, Cooper, \& Fairburn, 2002). Moreover, they support conceptions that striving for perfection is normal, healthy, and possibly adaptive when separated from negative aspects of perfectionism such as perfectionistic concerns, feelings of discrepancy, and harsh self-criticism (Dunkley, Blankstein, Masheb, \& Grilo, 2006; Rice et al., 1998; Shafran et al., 2002; Stoeber \& Otto, 2006). Finally, we believe that the present findings help to explain the "perfectionism paradox" that athletes may experience (Flett \& Hewitt, 2005), because they show that striving for perfection in athletes-while in itself positive-is often associated with negative reactions to imperfection which are related to maladaptive characteristics and outcomes.

\footnotetext{
${ }^{3}$ We are grateful to an anonymous reviewer for providing this observation.
} 
While we are aware of the controversies (and sensitivities) regarding the use of the terms positive, adaptive, functional, or healthy in combination with the term perfectionism in clinical and counseling psychology (e.g., Greenspon, 2000; see also Benson, 2003), our conclusions are in line with cumulative evidence from a recent review on positive conceptions of perfectionism (Stoeber \& Otto, 2006) which shows that the striving dimension of perfectionism is predominantly related to positive traits, attitudes, and outcomes. In contrast, the concerns dimension of perfectionism is exclusively related to negative traits, attitudes, and outcomes, and may adversely affect mental health (e.g., Rice \& Aldea, 2006; Dunkley, Sanislow, Grilo, McGlashan, 2006). Moreover, we are aware of the debate of the relative importance of individual dimensions of perfectionism in relation to the clinical relevance of the construct, as extensively discussed in Behaviour Research and Therapy (Dunkley, Blankstein, et al., 2006; Hewitt, Flett, Besser, Sherry, \& McGee, 2003; Shafran et al., 2002, 2003). Consequently, we would restrict our claims that perfectionism may have positive, adaptive, functional, or healthy aspects exclusively to the striving part of the construct and to non-clinical populations.

Regarding practical implications, the present findings may encourage athletes and their coaches to take a more differentiated view of perfectionism. Because of the wellestablished negative aspects of perfectionism, coaches may hesitate to encourage striving for perfection in athletes seeing that, as perfection and imperfection are opposites, it may be difficult for athletes to strive for perfection without reacting negatively to imperfection. However, an athlete who strives for perfection does not necessarily have to react negatively to imperfection. Even though the empirical correlation between striving for perfection and negative reactions to imperfection is relatively high, it is far from perfect. This indicates that there are athletes with strong strivings for perfection who do not show strong negative reactions to errors and mistakes during training and competition. Such athletes may represent role models of healthy perfectionists who-instead of being angry, frustrated, or depressed-accept their imperfections (Lundh, 2004) and, with a masteryapproach orientation in mind, see errors and mistakes as integral parts of the learning process and important for future improvements. Consequently, coaches may well encourage athletes' striving for perfection if, at the same time, they encourage athletes to focus on doing their best rather than worrying about mistakes, to enjoy their striving for excellence rather being afraid of falling short of expectations, and to concentrate on what has been achieved rather than pondering on what might have been achieved if everything had worked out perfectly. With such moderation, striving for perfectionism may help rather than undermine performance.

\section{References}

Ames, C., \& Archer, J. (1987). Mothers' belief about the role of ability and effort in school learning. Journal of Educational Psychology, 79, 409-414.

Anshel, M. H., \& Eom, H. J. (2003). Exploring the dimensions of perfectionism in sport. International Journal of Sport Psychology, 34, 255-271.

Benson, E. (2003). The many faces of perfectionism. Monitor on Psychology, 34(10), 18.

Bieling, P. J., Israeli, A., Smith, J., \& Antony, M. M. (2003). Making the grade: The behavioral consequences of perfectionism in the classroom. Personality and Individual Differences, 35, 163-178.

Bieling, P. J., Israeli, A. L., \& Antony, M. M. (2004). Is perfectionism good, bad, or both? Examining models of the perfectionism construct. Personality and Individual Differences, 36, 13731385. 
Chang, E. C. (2003). On the perfectibility of the individual: Going beyond the dialectic of good versus evil. In E. C. Chang \& L. J. Sanna (Eds.), Virtue, vice, and personality: The complexity of behavior (pp. 125-144). Washington, DC: American Psychological Association.

Conroy, D. E. (2004). The unique psychological meanings of multidimensional fears of failing. Journal of Sport and Exercise Psychology, 26, 484-491.

Conroy, D. E., \& Elliot, A. J. (2004). Fear of failure and achievement goals in sport: Addressing the issue of the chicken and the egg. Anxiety, Stress, and Coping, 17, 271-285.

Conroy, D. E., Elliot, A. J., \& Hofer, S. M. (2003). A $2 \times 2$ achievement goals questionnaire for sport: Evidence for factorial invariance, temporal stability, and external validity. Journal of Sport and Exercise Psychology, 25, 456-476.

Conroy, D. E., Kaye, M. P., \& Coatsworth, J. D. (2006). Coaching climates and the destructive effects of mastery-avoidance achievement goals on situational motivation. Journal of Sport and Exercise Psychology, 28, 69-92.

Cury, F., Da Fonséca, D., Rufo, M., Peres, C., \& Sarrazin, P. (2003). The trichotomous model and investment in learning to prepare for a sport test: A mediational analysis. British Journal of Educational Psychology, 73, 529-543.

DiBartolo, P. M., Frost, R. O., Chang, P., LaSota, M., \& Grills, A. E. (2004). Shedding light on the relationship between personal standards and psychopathology: The case for contingent selfworth. Journal of Rational Emotive and Cognitive Behavior Therapy, 22, 241-254.

Dunkley, D. M., Blankstein, K. R., Masheb, R. M., \& Grilo, C. M. (2006). Personal standards and evaluative concerns dimensions of "clinical" perfectionism: A reply to Shafran et al. (2002, 2003) and Hewitt et al. (2003). Behaviour Research and Therapy, 44, 63-84.

Dunkley, D. M., Sanislow, C. A., Grilo, C. M., \& McGlashan, T. H. (2006). Perfectionism and depressive symptoms 3 years later: Negative social interactions, avoidant coping, and perceived social support as mediators. Comprehensive Psychiatry, 47, 106-115.

Dunn, J. G. H., Dunn, J. C., Gotwals, J. K., Vallance, J. K. H., Craft, J. M., \& Syrotuik, D. G. (2006). Establishing construct validity evidence for the Sport Multidimensional Perfectionism Scale. Psychology of Sport and Exercise, 7, 57-79.

Dunn, J. G. H., Dunn, J. C., \& Syrotuik, G. (2002). Relationship between multidimensional perfectionism and goal orientations in sport. Journal of Sport and Exercise Psychology, 24, 376395.

Dweck, C. S. (1986). Motivational processes affecting learning. American Psychologist, 41, 10401048.

Elliot, A. J. (1997). Integrating the "classic" and "contemporary" approaches to achievement motivation: A hierarchical model of approach and avoidance achievement motivation. In P. Pintrich \& M. Maehr (Eds.), Advances in motivation and achievement (Vol. 10, pp. 143-179). Greenwich, CT: JAI Press.

Elliot, A. J., \& Church, M. A. (1997). A hierarchical model of approach and avoidance achievement motivation. Journal of Personality and Social Psychology, 72, 218-232.

Elliot, A. J., \& Conroy, D. E. (2005). Beyond the dichotomous model of achievement goals in sport and exercise psychology. Sport and Exercise Psychology Review, 1, 17-25.

Elliot, A. J., \& Harackiewicz, J. M. (1996). Approach and avoidance achievement goals and intrinsic motivation: A mediational analysis. Journal of Personality and Social Psychology, 70, 461-475.

Elliot, A. J., \& McGregor, H. A. (2001). A $2 \times 2$ achievement goal framework. Journal of Personality and Social Psychology, 80, 501-519.

Enns, M. W., \& Cox, B. J. (2002). The nature and assessment of perfectionism: A critical analysis. In G. L. Flett \& P. L. Hewitt (Eds.), Perfectionism: Theory, research, and treatment (pp. 3362). Washington, DC: American Psychological Association.

Enns, M. W., Cox, B. J., Sareen, J., \& Freeman, P. (2001). Adaptive and maladaptive perfectionism in medical students: A longitudinal investigation. Medical Education, 35, 1034-1042.

Flett, G. L., \& Hewitt, P. L. (2002). Perfectionism and maladjustment: An overview of theoretical, definitional, and treatment issues. In P. L. Hewitt \& G. L. Flett (Eds.), Perfectionism: Theory, research, and treatment (pp. 5-31). Washington, DC: American Psychological Association. 
Flett, G. L., \& Hewitt, P. L. (2005). The perils of perfectionism in sports and exercise. Current Directions in Psychological Science, 14, 14-18.

Flett, G. L., \& Hewitt, P. L. (2006). Positive versus negative perfectionism in psychopathology: A comment on Slade and Owens's dual process model. Behavior Modification, 30, 472-495.

Frost, R. O., \& Henderson, K. J. (1991). Perfectionism and reactions to athletic competition. Journal of Sport and Exercise Psychology, 13, 323-335.

Frost, R. O., Marten, P., Lahart, C., \& Rosenblate, R. (1990). The dimensions of perfectionism. Cognitive Therapy and Research, 14, 449-468.

Gould, D., Dieffenbach, K., \& Moffett, A. (2002). Psychological characteristics and their development in Olympic champions. Journal of Applied Sport Psychology, 14, 172-204.

Greenspon, T. S. (2000). "Healthy perfectionism" is an oxymoron! Reflections on the psychology of perfectionism and the sociology of science. Journal of Secondary Gifted Education, 11, 197-208.

Hall, H. K. (2006). Perfectionism: A hallmark quality of world class performers, or a psychological impediment to athletic development? In D. Hackfort \& G. Tenenbaum (Eds.), Essential processes for attaining peak performance (Vol. 1, pp. 178-211). Oxford, UK: Meyer \& Meyer.

Hall, H. K., Kerr, A. W., Kozub, S. A., \& Finnie, S. B. (in press). Motivational antecedents of obligatory exercise: The influence of achievement goals and multidimensional perfectionism. Psychology of Sport and Exercise.

Hall, H. K., Kerr, A. W., \& Matthews, J. (1998). Precompetitive anxiety in sport: The contribution of achievement goals and perfectionism. Journal of Sport and Exercise Psychology, 20, 194217.

Hamachek, D. E. (1978). Psychodynamics of normal and neurotic perfectionism. Psychology, 15, 27-33.

Hewitt, P. L., Flett, G. L., Besser, A., Sherry, S. B., \& McGee, B. (2003). Perfectionism is multidimensional: A reply to Shafran, Cooper and Fairburn (2002). Behaviour Research and Therapy, 41, 1221-1236.

Hill, R. W., Huelsmann, T. J., Furr, R. M., Kibler, J., Vicente, B. B., \& Kennedy, C. (2004). A new measure of perfectionism: The Perfectionism Inventory. Journal of Personality Assessment, 82, 80-91.

Jany, C., Stoll, O., \& Lang, F. R. (2004, May). Sportliche Zielorientierungen von Leistungssportlern [Sport-related goal orientations in competitive athletes]. Paper presented at the 9th asp-Nachwuchswerkstatt, Halle/Saale, Germany.

Lundh, L.-G. (2004). Perfectionism and acceptance. Journal of Rational Emotive and Cognitive Behavior Therapy, 22, 255-269.

Maehr, M. L., \& Meyer, H. A. (1997). Understanding motivation in schooling: Where we've been, where we are, and where we need to go. Educational Psychology Review, 9, 371-409.

Midgley, C., Kaplan, A., \& Middleton, M. (2001). Performance-approach goals: Good for what, for whom, under what circumstances, and at what cost? Journal of Educational Psychology, 93, 77-86.

Moller, A. C., \& Elliot, A. J. (2006). The $2 \times 2$ achievement goal framework: An overview of empirical research. In A. V. Mitel (Ed.), Focus on educational psychology research (pp. 307326). New York: Nova Science Publishers.

Munroe-Chandler, K. J., Hall, C. R., \& Weinberg, R. S. (2004). A qualitative analysis of the types of goals athletes set in training and competition. Journal of Sport Behavior, 27, 58-74.

Nicholls, J. G. (1984). Conceptions of ability and achievement motivation. In R. Ames \& C. Ames (Eds.), Research on motivation in education (Vol. 1, pp. 39-73). San Diego, CA: Academic Press.

Nunnally, J. C., \& Bernstein, I. (1994). Psychometric theory (3rd ed.). New York: McGraw-Hill.

Ommundsen, Y. (2004). Self-handicapping related to task and performance-approach and avoidance goals in physical education. Journal of Applied Sport Psychology, 16, 183-197.

Ommundsen, Y., Roberts, G. C., Lemyre, P.-N., \& Miller, B. W. (2005). Peer relationships in adolescent competitive soccer: Associations to perceived motivational climate, achievement goals and perfectionism. Journal of Sports Sciences, 23, 977-989. 
Pescheck, E. (2005). Leistungsängstlichkeit im Wettkampf: Eine Untersuchung bei SportschülerInnen [Competitive trait anxiety: An investigation with high-school student athletes]. Unpublished diploma thesis, Department of Psychology, Martin Luther University of Halle-Wittenberg, Germany.

Pintrich, P. R. (2000). An achievement goal theory perspective on issues in motivation terminology, theory, and research. Contemporary Educational Psychology, 25, 92-104.

Rice, K. G., \& Aldea, M. A. (2006). State dependence and trait stability of perfectionism: A shortterm longitudinal study. Journal of Counseling Psychology, 53, 205-212.

Rice, K. G., Ashby, J. S., \& Slaney, R. B. (1998). Self-esteem as a mediator between perfectionism and depression: A structural equation analysis. Journal of Counseling Psychology, 45, 304314.

Rice, K. G., \& Preusser, K. J. (2002). The Adaptive/Maladaptive Perfectionism Scale. Measurement and Evaluation in Counseling and Development, 34, 210-222.

Shafran, R., Cooper, Z., \& Fairburn, C. G. (2002). Clinical perfectionism: A cognitive-behavioural analysis. Behaviour Research and Therapy, 40, 773-791.

Shafran, R., Cooper, Z., \& Fairburn, C. G. (2003). "Clinical perfectionism" is not "multidimensional perfectionism": A reply to Hewitt, Flett, Besser, Sherry \& McGee. Behaviour Research and Therapy, 41, 1217-1220.

Skaalvik, E. M. (1997). Self-enhancing and self-defeating ego orientation: Relations with task and avoidance orientation, achievement, self-perceptions, and anxiety. Journal of Educational Psychology, 89, 71-81.

Slade, P. D., \& Owens, R. G. (1998). A dual process model of perfectionism based on reinforcement theory. Behavior Modification, 22, 372-390.

Slaney, R. B., Rice, K. G., Mobley, M., Trippi, J., \& Ashby, J. S. (2001). The revised Almost Perfect Scale. Measurement and Evaluation in Counseling and Development, 34, 130-145.

Spinath, B., Stiensmeier-Pelster, J., Schöne, C., \& Dickhäuser, O. (2002). Die Skalen zur Erfassung von Lern- und Leistungsmotivation (SELLMO) [The Scales for the Assessment of Learning and Performance Motivation]. Göttingen, Germany: Hogrefe.

Stöber, J., Otto, K., \& Stoll, O. (2004). Mehrdimensionales Inventar zu Perfektionismus im Sport (MIPS) [Multidimensional Inventory of Perfectionism in Sport (MIPS)]. In J. Stöber, K. Otto, E. Pescheck, \& O. Stoll, Skalendokumentation "Perfektionismus im Sport" (Hallesche Berichte zur Pädagogischen Psychologie No. 7, pp. 4-13). Halle/Saale, Germany: Martin Luther University of Halle, Department of Educational Psychology.

Stoeber, J. (2005). [Striving for perfection: Relations to multidimensional measures of perfectionism.] Unpublished raw data.

Stoeber, J., \& Otto, K. (2006). Positive conceptions of perfectionism: Approaches, evidence, challenges. Personality and Social Psychology Review, 10, 295-319.

Stoeber, J., Otto, K., Pescheck, E., Becker, C., \& Stoll, O. (2007). Perfectionism and competitive anxiety in athletes: Differentiating striving for perfection and negative reactions to imperfection. Personality and Individual Differences, 42, 959-969.

Stoeber, J., \& Rambow, A. (in press). Perfectionism in adolescent school students: Relations with motivation, achievement, and well-being. Personality and Individual Differences.

Stumpf, H., \& Parker, W. D. (2000). A hierarchical structural analysis of perfectionism and its relation to other personality characteristics. Personality and Individual Differences, 28, 837852.

Taris, T. W. (2000). A primer in longitudinal analysis. Thousand Oaks, CA: Sage.

Terry-Short, L. A., Owens, R. G., Slade, P. D., \& Dewey, M. E. (1995). Positive and negative perfectionism. Personality and Individual Differences, 18, 663-668.

Van Yperen, N. W. (2006). A novel approach to assessing achievement goals in the context of the $2 \times 2$ framework: Identifying distinct profiles of individuals with different dominant achievement goals. Personality and Social Psychology Bulletin, 32, 1432-1445. 
Table 1

Perfectionism and Achievement Goals: Correlations (Study 1)

\begin{tabular}{|c|c|c|c|c|c|c|c|c|}
\hline \multirow[b]{3}{*}{ Achievement goal } & \multicolumn{4}{|c|}{ Perfectionism during training } & \multicolumn{4}{|c|}{ Perfectionism during competition } \\
\hline & \multicolumn{2}{|c|}{ Correlation } & \multicolumn{2}{|c|}{ Partial correlation } & \multicolumn{2}{|c|}{ Correlation } & \multicolumn{2}{|c|}{ Partial correlation } \\
\hline & $\begin{array}{l}\text { Striving for } \\
\text { perfection }\end{array}$ & $\begin{array}{l}\text { Negative } \\
\text { reactions to } \\
\text { imperfection }\end{array}$ & $\begin{array}{l}\text { Striving for } \\
\text { perfection }\end{array}$ & $\begin{array}{l}\text { Negative } \\
\text { reactions to } \\
\text { imperfection }\end{array}$ & $\begin{array}{l}\text { Striving for } \\
\text { perfection }\end{array}$ & $\begin{array}{l}\text { Negative } \\
\text { reactions to } \\
\text { imperfection }\end{array}$ & $\begin{array}{l}\text { Striving for } \\
\text { perfection }\end{array}$ & $\begin{array}{c}\text { Negative } \\
\text { reactions to } \\
\text { imperfection }\end{array}$ \\
\hline Mastery & $.32 * * *$ & -.04 & $.37 * * *$ & $-.19 *$ & $.16^{*}$ & -.09 & $.21^{* *}$ & $-.16^{*}$ \\
\hline Performance-approach & $.28 * * *$ & $.26 * * *$ & $.19 * *$ & $.16^{*}$ & $.19 * *$ & $.25 * * *$ & .11 & $.20 * *$ \\
\hline Performance-avoidance & .13 & $.38 * * *$ & -.02 & $.36 * * *$ & .02 & $.39 * * *$ & $-.14^{*}$ & $.41^{* * *}$ \\
\hline
\end{tabular}

Note. $N=204$ high school athletes. Correlation = zero-order correlation. Partial correlation = correlation of striving for perfection controlling for negative reactions to imperfection and correlation of negative reactions to imperfection controlling for striving for perfection, respectively. ${ }^{*} p<.05,{ }^{* *} p<.01$, *** $p<.001$, two-tailed. 
Table 2

Perfectionism and Achievement Goals: Correlations at T1(Study 2)

\begin{tabular}{|c|c|c|c|c|c|c|c|c|}
\hline \multirow[b]{3}{*}{ Achievement goal } & \multicolumn{4}{|c|}{ Perfectionism during training } & \multicolumn{4}{|c|}{ Perfectionism during competition } \\
\hline & \multicolumn{2}{|c|}{ Correlation } & \multicolumn{2}{|c|}{ Partial correlation } & \multicolumn{2}{|c|}{ Correlation } & \multicolumn{2}{|c|}{ Partial correlation } \\
\hline & $\begin{array}{l}\text { Striving for } \\
\text { perfection }\end{array}$ & $\begin{array}{l}\text { Negative } \\
\text { reactions to } \\
\text { imperfection }\end{array}$ & $\begin{array}{l}\text { Striving for } \\
\text { perfection }\end{array}$ & $\begin{array}{c}\text { Negative } \\
\text { reactions to } \\
\text { imperfection }\end{array}$ & $\begin{array}{l}\text { Striving for } \\
\text { perfection }\end{array}$ & $\begin{array}{l}\text { Negative } \\
\text { reactions to } \\
\text { imperfection }\end{array}$ & $\begin{array}{l}\text { Striving for } \\
\text { perfection }\end{array}$ & $\begin{array}{c}\text { Negative } \\
\text { reactions to } \\
\text { imperfection }\end{array}$ \\
\hline Mastery-approach & $.50 * * *$ & $.29 * * *$ & $.42 * * *$ & -.04 & $.49 * * *$ & $.23 * *$ & $.45 * * *$ & -.06 \\
\hline Mastery-avoidance & .06 & $.27 * * *$ & -.10 & $.28 * * *$ & $.21^{*}$ & $.42 * * *$ & -.03 & $.37 * * *$ \\
\hline Performance-approach & $.34 * * *$ & $.37 * * *$ & $.18^{*}$ & $.24 * * *$ & $.35^{* * *}$ & $.35^{* * *}$ & $.20 *$ & $.20 *$ \\
\hline Performance-avoidance & .12 & .15 & -.04 & .11 & .10 & $.22 * *$ & -.02 & $.19 *$ \\
\hline
\end{tabular}

Note. $N=147$ university student athletes. T1 = Time 1 . Correlation = zero-order correlation. Partial correlation = correlation of striving for perfection controlling for negative reactions to imperfection and correlation of negative reactions to imperfection controlling for striving for perfection, respectively.

${ }^{*} p<.05,{ }^{* *} p<.01,{ }^{* * *} p<.001$, two-tailed. 


\section{Table 3}

Summary of Hierarchical Regression Analyses for Perfectionism at T1 Predicting Changes in Achievement Goals from T1 to T2 (Study 2)

\begin{tabular}{|c|c|c|c|c|c|c|c|c|}
\hline \multirow[b]{3}{*}{ Variable } & \multicolumn{8}{|c|}{ Achievement goal T2 } \\
\hline & \multicolumn{2}{|c|}{$\begin{array}{c}\text { Mastery- } \\
\text { approach T2 }\end{array}$} & \multicolumn{2}{|c|}{$\begin{array}{c}\text { Mastery- } \\
\text { avoidance T2 }\end{array}$} & \multicolumn{2}{|c|}{$\begin{array}{l}\text { Performance- } \\
\text { approach T2 }\end{array}$} & \multicolumn{2}{|c|}{$\begin{array}{l}\text { Performance- } \\
\text { avoidance T2 }\end{array}$} \\
\hline & $\beta$ & $\Delta R^{2}$ & $\beta$ & $\Delta R^{2}$ & $\beta$ & $\Delta R^{2}$ & $\beta$ & $\Delta R^{2}$ \\
\hline Achievement goal T1 & $.62 * * *$ & & $.73^{* * *}$ & & $.79 * * *$ & & $.65^{* * *}$ & \\
\hline Step 2 & & $.05 *$ & & $.05^{* * *}$ & & .00 & & .02 \\
\hline Achievement goal T1 & $.51 * * *$ & & $.64^{* * *}$ & & $.80^{* * *}$ & & $.68^{* * *}$ & \\
\hline Striving for perfection T1 & .18 & & -.10 & & -.04 & & -.13 & \\
\hline
\end{tabular}

Note. $N=103$ university student athletes. T1 = Time 1 , T2 = Time 2 (two to three months later). Achievement goal T1 = mastery-approach T1, mastery-avoidance T1, performance-approach T1, and performance-avoidance T1, for regressions 1-4 respectively. Striving for perfection T1 = combined score of striving for perfection during training at T1 and striving for perfection during competition at T1. Negative reactions to imperfection T1 = combined score of negative reactions during training at T1 and negative reactions to imperfection during competition at T1.

${ }^{*} p<.05,{ }^{* * *} p<.001$, two-tailed. 


\section{Appendix}

Perfectionism During Training and Competition: Scales and Items

\section{Striving for Perfection}

1. I strive to be as perfect as possible.

2. It is important to me to be perfect in everything I attempt.

3. I feel the need to be perfect.

4. I am a perfectionist as far as my targets are concerned.

5. I have the wish to do everything perfectly.

\section{Negative Reactions to Imperfection}

1. I feel extremely stressed if everything doesn't go perfectly.

2. I get completely furious if I make mistakes.

3. I get frustrated if I do not fulfill my high expectations.

4. I feel depressed if I have not been perfect.

5. If something does not go perfectly, I am dissatisfied with the whole [training session, competition/game].

Note. To measure striving for perfection during training and negative reactions during training, all items are presented with the prefix "During training." To measure striving for perfection during competition and negative reactions to imperfection during competition, all items are presented with the prefix "During competition/league games" except for Item 4 and 5 of the negative reactions to imperfection subscale: Item 4 is presented with the prefix "After training" and "After competition/league games,” respectively, and Item 5 has no prefix, but instead reads “If something doesn't go perfectly during training, I am dissatisfied with the whole training session" and "If something doesn't go perfectly during competition/league games, I am dissatisfied with the whole competition/game,” respectively. 